\title{
In vitro anti-Candida activity and mechanism of action of the flavonoid isolated from Praxelis clematidea against Candida albicans species
}

\author{
Abrahão Alves de Oliveira Filho ${ }^{1}$, Heloísa Mara Batista Fernandes de Oliveira ${ }^{2 *}$, Janiere Pereira de Sousa ${ }^{2}$, Déborah \\ Ribeiro Pessoa Meireles ${ }^{2}$, Gabriela Lemos de Azevedo Maia ${ }^{3}$, José Maria Barbosa Filho ${ }^{2}$, José Pinto de Siqueira \\ Júnior $^{2}$, Edeltrudes Oliveira Lima ${ }^{2}$ \\ ${ }^{1}$ Academic Unit Biological Sciences, Federal University of Campina Grande, Paraiba, Brazil. ${ }^{2}$ Programin Natural Productsand SyntheticBioactive, Federal \\ University of Paraiba, Paraiba, Brazil. ${ }^{3}$ Department of Pharmacy, Federal University ofSão Francisco Valley, Pernambuco, Brazil.
}

\section{ARTICLE INFO}

\section{Article history:}

Received on: 03/10/2015

Revised on: $15 / 11 / 2015$

Accepted on: 30/11/2015

Available online: 26/01/2016

Key words:

Flavonoid, antifungal,

Candida, Praxelis clematidea.

\begin{abstract}
The prevalence of candidiasis in the world is high. Candida species are able to create superficial and systemic infections. Candida albicans is an opportunistic pathogen, causing mycoses in immunocompromised patients as well as long-term antibiotic users. The present study objective was to evaluate in vitro anti-Candida effect of this compost isolated from Praxelis clematidea. The minimum inhibitory concentration (MIC) and the minimum fungicidal concentration (MFC) were determined by the broth microdilution techniques. We also investigated possible flavonoid 5,7,4 trimethoxflavone (TMF) action on cell walls ( $0.8 \mathrm{M}$ sorbitol) and cell membranes (TMF to ergosterol binding). The $\mathrm{MIC}_{50}$ of flavonoid were $64 \mu \mathrm{g} / \mathrm{mL}$ and tha $\mathrm{MFC}_{50}$ was $64 \mu \mathrm{g} / \mathrm{mL}$. Involvement with the cell wall and ergosterol binding were comproved as possible mechanisms of action. In conclusion the flavonoid showed in vitro antifungal potential against strains of $C$. albicans.
\end{abstract}

\section{INTRODUCTION}

Fungal diseases represent a critical problem to health and they are one of the main causes of morbidity and mortality worldwide. Human infections, particularly those involving the skin and mucosal surfaces, constitute a serious problem, especially in tropical and subtropical developing countries (Portillo et al., 2001). In humans, fungal infections range from superficial to deeply invasive or disseminated, and have increased dramatically in recent years. Although new drugs have been introduced to combat this problem, the development of resistance to antifungal drugs has become increasingly apparent, especially in patients who require long-term treatment or who are receiving antifungal prophylaxis, and there is growing awareness of shifts of flora to more-resistant species (Pradeepa et al., 2014). Fungal infections are usually associated with Candida, Aspergillus and Cryptococcus species but those due to Candida species represent the main opportunistic fungal infections

\footnotetext{
* Corresponding Author

Heloisa Mara Batista Fernandes de Oliveira, Program in Natural Products and Synthetic Bioactive, Federal University of Paraiba, Paraiba-Brazil.Email: Mail id:heloisambf@gmail.com
}

worldwide, leading to high morbidity and mortality in the population (Low and Rotstein, 2011). These changes are linked to the growing population of immuno-compromised patients. During the last three decades, Candida albicans has been the most prevalent pathogen in systemic fungal infections (Pfaller and Diekema, 2004). Although the antifungal active principles are diverse and numerous, only few classes of antifungal agents are currently available to treat yeast infections due to the high toxicity of many of them (Spampinato and Leonardi, 2013). The high morbidity and mortality rates associated with opportunistic yeast infections indicate that current anti-fungal therapy to combat candidiasis is still ineffective (Dzoyem et al., 2014).

Therefore, it has become essential to develop new drugs and alternative therapies (including natural products) for treatment of Candida albicans infections. Plants and their derivatives are known to be important in pharmacological research due to their great potential as a source for a variety of biologically active ingredients used in drug development. Amongst these products we find the flavonoids that are considered as constitutive antimicrobial ingredients, especially those belonging to prenylated flavonoids, flavones and isoflavones (Filho et al., 2012; Leite et al., 2014). 
Considering the few studies on the antifungal effects of the flavonoid 5, 7, 4'-trimethoxyflavone (TMF), the aim of the present study was to evaluate in vitro anti-Candida effect of this compost isolated from Praxelis clematidea.

\section{MATERIALS AND METHODS}

\section{Isolated of the flavonoid}

Maia et al. (2011) describe the method of obtaining the flavonoid.

\section{Fungal strains}

For antifungal activity assays, were selected 8 strains of fungi (Candida albicans - LM 86, Candida albicans - LM 111, Candida albicans - LM 122, Candida albicans - LM 108, Candida albicans - LM 20, Candida albicans - LM 189, Candida albicans - ATCC 90028, Candida albicans - ATCC 76645). All the microorganism strains were obtained from the Laboratory of Mycology collection. Fungi was kept on Nutrient Agar (NA) slants at $4{ }^{\circ} \mathrm{C}$. Inocula were obtained from overnight cultures grown on NA slants at $37{ }^{\circ} \mathrm{C}$ and diluted in sterile saline solution $(\mathrm{NaCl}$ $0.85 \% \mathrm{w} / \mathrm{v}$ ) to provide a final concentration of approximately 106 count forming unit per $\mathrm{mL}\left(\mathrm{CFU} \cdot \mathrm{mL}^{-1}\right)$ adjusted according to the turbidity of $0.5 \mathrm{McF}$ arland scale tube.

\section{Determination of the minimum inhibitory concentration (MIC) and minimum fungicide concentration (MFC)}

The microplate bioassay was used to determine the minimum inhibitory concentration (MIC) of flavonoid (Viljoen et al., 2003; Sahin et al., 2004). One hundred milliliters $(100 \mu \mathrm{L})$ of liquid medium RPMI-1640 was transferred into the wells of a 96well microdilution plate with a "U" shaped bottom (Alamar, Diadema, SP, Brazil).Then, $100 \mu \mathrm{L}$ of flavonoid emulsion was inoculated in the first horizontal row of the plate wells. Doubled serial dilutions, where a $100 \mu \mathrm{L}$ aliquot removed from the most concentrated well went to the next well, and yielded concentrations of 1024-16 $\mu \mathrm{g} / \mathrm{mL}$. Finally, $10 \mu \mathrm{L}$ of $C$. albicans inoculum suspension was added to each well of the plate, where each column represented a yeast strain. In parallel, controls were made for yeast viability and for susceptibility with the standard antifungal Nystatin $(100 \mathrm{UI} / \mathrm{mL})$. To verify the absence of interference in the results for the solvent used in the preparation of the substance in the event the cremophor, in which a control was placed in the cavities $100 \mu \mathrm{L}$ of the double-concentrated broth, $100 \mu \mathrm{L}$ of cremophor and $10 \mu \mathrm{L}$ of the suspension was made. The plates were incubated at $35^{\circ} \mathrm{C}$ for $24-48 \mathrm{~h}$.

After the appropriate incubation time, the presence (or absence) of growth was observed visually. The formation of cell clusters or "buttons" in the plate wells was considered. The MIC was defined as the lowest TMF concentration that produced visible inhibition of yeast growth.

To determine the MFC, we subcultured $20 \mu \mathrm{L}$ aliquots of $\mathrm{MIC}, \mathrm{MIC} \times 2$, and MIC $\times 4$ of the TMF, and the control yeast growth onto Petri dishes containing SDA. After 24-48 hours of incubation at $35^{\circ} \mathrm{C}$, a reading was made to evaluate the MFC, as based on the growth of the controls. The MFC was defined as the lowest product concentration that inhibited growth of the yeast or permitted less than three CFUs to occur, resulting thus in $99.9 \%$ fungicidal activity (Ernst et al., 1996, Espinel-Ingroff et al., 2002). Biological activity assays were performed in duplicate, and the results were expressed as the arithmetic mean of the MIC and MFC.

\section{Sorbitol assay-effect of TMF on the cell wall of $C$. albicans}

The assay was performed using medium with and without sorbitol (control) to evaluate possible mechanisms involved in the antifungal activity of the test product on the yeast cell wall.

The sorbitol was added to the culture medium in a final concentration of $0.8 \mathrm{M}$. The assay was performed by microdilution method in 96-well plates in a "U" (Alamar, Diadema, SP, Brazil). The plates were sealed aseptically, incubated at $35^{\circ} \mathrm{C}$, and readings were taken at 2 and 7 days. Based on the ability of sorbitol to act as a fungal cell wall osmotic protective agent, the higher MIC values observed in the medium with added sorbitol compared to the standard medium implicated the cell wall as one of the possible cell targets for the product tested (Frost et al., 1995). The assay was performed in duplicate and expressed as the geometric mean of the results.

\section{Ergosterol binding assay-MIC value determination in presence of ergosterol}

To assess if the product binds to the fungal membrane sterols, this experiment was performed according to the method described by Escalante et al. (2008), with some modifications. The ergosterol was prepared at the time of test execution, where it was first pulverized (with the help of a pre-sterilized porcelain mortar and pestle) and dissolved in DMSO (no more than $10 \%$ of final volume), and Tween 80 at $1 \%$, in accordance with the desired concentration and volume. The formed emulsion was then homogenized, heated to augment the solubility, and diluted with the liquid culture medium.

The MIC of TMF against $C$. albicans was determined by using broth microdilution techniques according to the guidelines of the CLSI for yeasts (M27-A3) (CSLI, 2008), in the presence and absence of exogenous ergosterol (Sigma-Aldrich, São Paulo, SP, Brazil) added to the assay medium, in different lines of the same microplate. Briefly, a solution of flavonoid was doubly diluted serially with RPMI-1640 (volume $=100 \mu \mathrm{L}$ ) containing plus ergosterol at concentration of $400 \mu \mathrm{g} / \mathrm{mL}$.

A volume of $10 \mu \mathrm{L}$ of yeast suspension ( $0.5 \mathrm{McFarland})$ was added to each well. The plates were sealed and incubated at $35^{\circ} \mathrm{C}$. The plates were read after $24 \mathrm{~h}$ of incubation and MIC was determined as the lowest concentration of test agent inhibiting the visible growth. This assay was carried out in duplicate and the geometric mean values were calculated. Thus, this binding assay reflected the ability of compound to bind with the ergosterol. 


\section{RESULTS AND DISCUSSION}

Nowadays, fungal diseases have emerged and are being increasingly recognized as important public health problems owing to an ever-expanding population of immunocompromised patients (Miceli et al., 2011). Linked to this the prevalence of candidiasis has been increased. Candida species are able to create superficial and systemic infections. Candida albicans is an opportunistic pathogen, causing mycoses in immunocompromised patients as well as long-term antibiotic users (Zhang et al., 2002).

Furthermore Pierce and Lopez-Ribolt et al. (2013) reported that, the current arsenal of antifungal drugs is exceedingly short and no new antifungal drugs are expected to reach the market any time soon. Therefore, the discovery of new antimicrobial agents is still relevant. Among the potential sources of new agents, plants have long been investigated because they contain many bioactive compounds that can be of interest in therapy. Because of their low toxicity, there is growing interest in using spices as a source of bio- active phytochemicals for their antimicrobial properties in preventing pathogenic diseases, in addition to their flavor and fragrance qualities (Arora and Kaur, 1999). The results for TMF's antifungal activity against $C$. albicans strains were determined using the MIC and MFC in broth microdilutions (Table 1). The $\mathrm{MIC}_{50}$ (minimum inhibitory concentration able to inhibit $50 \%$ of the fungal strains) of TMF was $64 \mu \mathrm{g} / \mathrm{mL}$, inhibiting the growth of all tested fungal strains. The results for the negative control (cremophor) showed no fungal growth inhibition, the results for the positive control (nystatin) showe fungal growth inhibition and fungal growth in the medium without added drug was detected (sterile control). The $\mathrm{MFC}_{50}$ (minimum fungicid concentration able to inhibit $50 \%$ of the fungal strains) of TMF was $64 \mu \mathrm{g} / \mathrm{mL}$.

Table 1: Antifungal activity for determination of the MIC and MFC of the TMF.

\begin{tabular}{lcccc}
\hline $\begin{array}{c}\text { Substance / } \\
\text { Fungal strains }\end{array}$ & $\begin{array}{c}\text { TMF } \\
\text { (MIC } \\
\boldsymbol{\mu g} / \mathbf{m L})\end{array}$ & $\begin{array}{c}\text { TMF } \\
\text { (MFC } \\
\boldsymbol{\mu g / m L})\end{array}$ & $\begin{array}{c}\text { Negative } \\
\text { control }\end{array}$ & $\begin{array}{c}\text { Positive } \\
\text { control }\end{array}$ \\
\hline C. albicans (ATCC 90028) & 32 & 64 & - & + \\
C. albicans (ATCC 76645) & 32 & 64 & - & + \\
C. albicans (LM 20) & 64 & - & - & + \\
C. albicans (LM 86) & 512 & 1024 & - & + \\
C. albicans (LM 108) & 64 & - & - & + \\
C. albicans (LM 111) & 64 & 64 & - & + \\
C. albicans (LM 122) & 64 & 64 & - & + \\
C. albicans (LM 189) & 64 & 64 & - & + \\
\hline
\end{tabular}

(-) No inhibition (+) inhibition

According with literature results strong activity is for MIC values between $0.05-0.50 \mathrm{mg} / \mathrm{mL}$, moderate activity MIC values between $0.6-1.50 \mathrm{mg} / \mathrm{mL}$ and weak activity above 1.50 $\mathrm{mg} / \mathrm{mL}$ (Sartoratto et al., 2004). The results showed that TMF present de strong effect against $C$. albicans strains with $\mathrm{MIC}_{50}$ for TMF is $64 \mu \mathrm{g} / \mathrm{mL}$. These results are in agreement with the data obtained by Filho et al. (2012) in their study using the flavonoid TMF against various strains of Candida. Analyzing the results of the MFC can be seen that the flavonoid does have fungicide activity against $C$. albicans species, because when the ratios of MFC/MIC were 1 or 2 , indicating that the effect of the compound was fungicide in nature (and not fungistatic) (Hafidh et al., 2011).

In accordance with the above results, the strains ATCC 76645 and LM 122 were selected for further testing. The MIC for TMF both strains was $64 \mu \mathrm{g} / \mathrm{mL}$. To investigate the action of the product on the fungal cell wall we performed an assay with sorbitol, which has an osmoprotectant function. Sorbitol is an osmotic protector used to stabilize fungi protoplasts. Specific fungal cell wall inhibitors share a distinctive characteristic where their antifungal effects are reversed in mediums containing sorbitol (Frost et al., 1995). Cells protected with sorbitol can grow in the presence of fungal cell wall inhibitors, whereas growth would be inhibited in the absence of sorbitol. This effect is detected by increases in the MIC value as observed in medium with sorbitol as compared to the MIC value in medium without sorbitol (standard medium) (Frost et al., 1995; Svetaz et al., 2007). Osmotic destabilizing agents and disrupting the cell wall lead to rearrangements of the cell wall and allow the fungal cells to survive (CSLI, 2002). In this paper, the MIC values of TMF in experiments, in mediums with sorbitol (Table 2), were increased, suggesting that flavonoid does act by inhibiting fungal cell wall synthesis.

Table 2: Antifungal activity of the TMF in presence and absence of sorbitol $(0.8 \mathrm{M})$.

\begin{tabular}{lccc}
\hline \multicolumn{1}{c}{$\begin{array}{c}\text { Substance / } \\
\text { Fungal strains }\end{array}$} & $\begin{array}{c}\text { TMF } \\
(\mathbf{M I C} \\
\boldsymbol{\mu g} / \mathbf{m L})\end{array}$ & $\begin{array}{c}\text { TMF (MIC } \\
\boldsymbol{\mu g} / \mathbf{m L}) \\
+\mathbf{s o r b i t o l}(\mathbf{0 . 8} \mathbf{~ M})\end{array}$ & $\begin{array}{c}\text { Negative } \\
\text { control }\end{array}$ \\
\hline C. albicans (ATCC 76645) & 32 & 256 & - \\
C. albicans (LM 122) & 64 & 1024 & - \\
\hline
\end{tabular}

(-) No inhibition.

Considering this possible fungal cell membrane interference of TMF, the compound was tested to investigate its ability to form complexes with ergosterol. Ergosterol is the principal sterol present in yeasts and filamentous fungi, where it is necessary for the growth and normal function of the fungal cell membrane. Besides controlling the fluidity, asymmetry and integrity of the membrane, ergosterol contributes to the proper functioning of enzymes bound to the membrane (Alves et al., 2013). Ergosterol plays the same role in fungal membranes that cholesterol plays in mammalian cell membranes (Bowman and Free, 2006). Thus, these two sterols seem to exhibit qualitatively similar properties. The majority of existing drugs for the treatment of fungal infections target the cell wall or plasma membrane directly or indirectly, particularly ergosterol and its biosynthesis (Odds et al., 2003; Lupetti et al., 2002).

If the activity of flavonoid is caused by binding to ergosterol, the exogenous ergosterol would prevent the binding to ergosterol in the fungal membranes. Consequently, MIC increase for TMF (in the presence of exogenous ergosterol in relation to the control assay) would occur because only increased product concentration in the growth medium might assure interaction with ergosterol in the fungal membranes (Escalante et al., 2008; Lunde 
et al., 2000). Thus, the effect of exogenous ergosterol on TMF's MIC was determined. As can be seen, flavonoid displayed changes in MIC values; the values were increased in medium with additional ergosterol (Table 3). This indicates that the mechanism of action of TMF does involve too complexation with ergosterol.

Table 3: Antifungal activity of the TMF in presence and absence of ergosterol $(400 \mu \mathrm{g} / \mathrm{mL})$.

\begin{tabular}{lccc} 
Substance / & TMF & TMF (MIC & \\
Fungal strains & $\begin{array}{c}\text { (MIC } \\
\boldsymbol{\mu g} / \mathbf{m L})\end{array}$ & $\begin{array}{c}\boldsymbol{\mu g} / \mathbf{m L})+ \\
\mathbf{e r g o s t e r o l} \\
(\mathbf{4 0 0} \boldsymbol{\mu g} / \mathbf{m L})\end{array}$ & $\begin{array}{c}\text { Negative } \\
\text { control }\end{array}$ \\
\hline C. albicans(ATCC 76645) & 32 & 128 & - \\
C. albicans (LM 122) & 64 & 512 & - \\
\hline
\end{tabular}

(-) No inhibition

\section{CONCLUSION}

Based on these results, the present study demonstrated that flavonoid TMF has significant antifungal activity against $C$. albicans. Another important aspect was that the probable mechanism of action does involve interactions either the cell wall or ergosterol. Therefore, the test product is presented as a relevant and promising antifungal which can be considered as an alternative prototype for production of a new and future antifungal, and thus contributing to the existing arsenal of products with proven antifungal activity against $C$. albicans.

\section{COMPETING INTERESTS}

The authors declared no potential conflicts of interest.

\section{REFERENCES}

Alves LA, Freires IA, Pereira TM, Souza A, Lima EO, Castro RD. Effect of Schinus terebinthifolius on Candida albicans growth kinetics, cell wall formation and micromorphology. Acta Odontol Scand, 2013; 71: 965-971.

Arora DS, Kaur J. Antimicrobial activity of spices. Int J Antimicrob Agents, 1999; 12: 257-262.

Bowman SM, Free SJ. The structure and synthesis of the fungal cell wall. BioEssays, 2006; 28(8): 799-808.

CLSI. Reference method for broth dilution antifungal susceptibility testing of yeasts. CLSI document M27-A3, 2008; 28(14): 10.

Dzoyem JP, Tchuenguem RT, Kuiate JR, Teke GN, Kechia FA. In vitro and in vivo antifungal activities of selected Cameroonian dietary spices. BMC Complementary Altern Med, 2014; 14:58.

Ernst ME, Klepser ME, Wolfe EJ, Pfaller MA. Antifungal dynamics of LY 303366, an investigational echinocandin B analog, against Candida ssp.," Diagn Micro Infect Dis, 1996; 26(3-4): 125-131.

Escalante A, Gattuso M, P'erez P, Zacchino S. Evidence for the mechanism of action of the antifungal phytolaccoside $\mathrm{B}$ isolated from Phytolacca tetramera Hauman. J Nat Products, 2008; 71(10): 1720-1725.

Espinel-Ingroff A, Chaturvedi V, Fothergill A, Rinaldi MG. Optimal testing conditions for determiningMICs and minimum fungicidal concentrations of new and established antifungal agents for uncommon molds: NCCLS collaborative study. J Clin Microbiol, 2002; 40(10): 37763781 .

Filho AAO, Fernandes HMB, Sousa JP, Maia GLA, Tavares JF, Barbosa-Filho JM, Lima EO, Oliveira TL. Antifungal Potential of the Flavonoid Isolated from Praxelis clematidea R.M. King \& Robinson. Lat Am J Pharm, 2012; 31 (7): 1064-6.

Frost DJ, Brandt KD, Cugier D, Goldman R. A whole-cell Candida albicans assay for the detection of inhibitors towards fungal cell wall synthesis and assembly. J Antibiotics, 1995; 48(4): 306-310.
Hafidh RR, Abdulamir AS, Vern LS, Bakar FA, Abas F, Jahanshiri F, Sekawi Z. Inhibition of growth of highly resistant bacterial and fungal pathogens by a natural product. Open Microbiol J, 2011; 5: 96106.

Leite MCA, Bezerra APB, Sousa JP, Guerra FQS, Lima EO. Evaluation of antifungal activity and mechanism of action of Citral against Candida albicans. J Evid Based Complementary Altern Med, 2014; 1-9.

Low CY, Rotstein C. Emerging fungal infections in immunocompromised patients. F1000 Med Rep, 2011; 3:14.

Lupetti A, Danesi R, Campa M, Del Tacca M, Kelly S. Molecular basis of resistance to azole antifungals. Trends Mol Med, 2002; 8: 76-81.

Lunde CS, Kubo I. Effect of polygodial on themitochondrial ATPase of Saccharomyces cerevisiae. Antimicrob Agents Chem, 2000; 44(7): 1943-1953.

Maia GLA, Falcão-Silva VS, Aquino PGV, Araújo-Júnior JX, Tavares JF, Silva MS, Rodrigues LC, Siqueira-Júnior JP, Barbosa-Filho JM. Flavonoids from Praxelis clematidea R.M. King and Robinson Modulate Bacterial Drug Resistance. Molecules, 2011; 16: 4828-4835.

Miceli MH, Diaz JA, Lee SA. Emerging opportunistic yeast infections. Lancet Infect Dis 2011; 11: 142-151.

Odds FC, Brown AJP, Gow NAR. Antifungal agents: mechanisms of action. Trends Microbiol, 2003; 11: 272-279.

Pfaller MA, Diekema DJ. Rare and emerging opportunistic fungal pathogens: concern for resistence beyond Candida albicans and Aspergillus fumigants. J Clin Microbiol, 2004; 42:4419-4431.

Pierce CG, Lopez-Ribolt JL. Candidiasis drug discovery and development: new approaches targeting virulence for discovering and identifying new drugs. Expert Opin Drug Discov. 2013; 8: 1117-1126.

Portillo A, Vila R, Freixa B, Adzet T. Cañigueral S. Antifungal activity Paraguayan plants used in traditional medicine. J Ethnopharmacol, 2001; 76(1):93-98.

Pradeepa A, Subramanian S, Kaviyarasan V. Evaluation of antimicrobial activity of Pithecellobium dulce pod pulp extract. Asian J Pharm Clin Res, 2014; 7(1): 32-37.

Sahin F, Güllüce M, Daferera D, Sökmen A, Sökmen M, Polissiou M, Agar G, Özer H. Biological activities of the essential oils and methanol extract of Origanum vulgare ssp. vulgare in the Eastern Anatolia region of Turkey. Food Control, 2004; 15: 549-557.

Sartoratto A, Machado ALM, Delarmelina C, Figueira GM, Duarte MCT, Rehder VLG. Composition and antimicrobial activity of essential oils from aromatic plants used in Brazil. Braz J Microbiol, 2004; 35: $275-280$

Spampinato C, Leonardi D. Candida infections, causes, targets and rsistance mechanism: traditional and alternative antifungal agents BioMed Res Int, 2013; 204-237.

Svetaz L, Agüero MB, Alvarez S, Luna L, Feresin G, Derita M, Tapia A, Zacchino S. Antifungal activity of Zuccagnia punctata Cav.: evidence for the mechanism of action. Planta Med, 2007; 73(10): 10741080 .

Viljoen A, Vuuren SV, Ernst E, Lepser M, Demirci B, Baser H, Van Wyk BE.Osmitopsis astericoides (Asteraceae) - the antimicrobial activity and essential oil composition of a Cape-Dutch remedy. J Ethnopharmacol, 2003; 88: 137-143.

Zhang Z, ElSohly HN, Jacob MR, Pasco DS, Walker LA, Clark AM. Natural products inhinbiting Candia albicans secret aspartic proteases from Tovomita krukovii. Planta Med, 2002; 68(1): 49-54.

\section{How to cite this article:}

deOliveira Filho AA, de Oliveira HMBF, Sousa JP, Meireles D, de Azevedo Maia GL, Filho JMB, Lima EO. In vitro anti-Candida activity and mechanism of action of the flavonoid isolated from Praxelis clematidea against Candida albicans species. J App Pharm Sci, 2016; 6 (01): 066-069. 